\title{
EFFECTIVENESS OF CLOZAPINE, HALOPERIDOL AND CHLORPROMAZINE IN SCHIZOPHRENIA DURING A FIVE-YEAR PERIOD
}

\author{
Dragan B. Ravanic', Slavica M. Djukic Dejanovic', Vladimir Janjic', Suzana D. Jovic', Dragan R. Milovanovic ${ }^{2}$, \\ Vladimir Jakovljevic', Vesna Pantovic ${ }^{3}$,Boris Ravanic', Maja Pantovic ${ }^{3}$, Mihailo M. Pantovic ${ }^{3}$
}

\begin{abstract}
Objective: The aim of our study was to evaluate the effects of low doses of clozapine in flexible regime in comparison with haloperidol and chlorpromazine in long term. Method: The naturalistic study was prospective, active-controlled with 325 adult outpatients of both genders ( 140 females), with mean year age of 34.8 (range 21-57), suffering from chronic schizophrenia. The first onset of illness was at the mean of 27.9 years (range 17-38), and subjects had the mean year age of $4.1 \pm 0.5$ previous relapses. The patients were allocated to receive haloperidol (105 subjects, dose range 2-15 mg), chlorpromazine ( $n=105,100-400 \mathrm{mg}$ ) or clozapine $(\mathrm{n}=115,75-600 \mathrm{mg}$ ). The scores of psychometric instruments (GWB, PANSS, CGI) were regularly assessed during 5 year period. Results: The sixty-six responders were included in per-protocol analysis: 12,10 and 16 with positive and 7, 6 and 15 with negative schizophrenic syndrome in haloperidol, chlorpromazine and clozapine group, respectively. The statistically significant differences in all psychometric scores was found, for both schizophrenic syndromes, favoring clozapine. The distribution of eighteen different types of adverse events, which we noted, were significantly different among treatment groups $\left(\chi^{2}=315.7, d f=34, p<0.001\right)$. Clozapine was safer and had fewer adverse effects (average of 0.9 adverse events per patient) than haloperidol (2.7) and chlorpromazine (3.2). Conclusions: Clozapine, in low doses of flexible regime, in long term (five years) showed better effectiveness in chronic schizophrenics with positive and negative symptoms than typical antipsychotics.
\end{abstract}

KEY WORDS: schizophrenia, antipsychotics drugs, long-term outcomes, clinical practice.

\begin{abstract}
Eficácia da clozapina, haloperidol e clorpromazina na esquizofrenia em um período de cinco anos
Resumo - Objetivo: O propósito deste estudo foi avaliar os efeitos de baixas doses de clozapina em regime flexível comparando com o uso de haloperidol e clorpromazina por período de 5 anos. Método: Um estudo prospectivo naturalístico, ativo-controlado foi realizado com 325 pacientes com idade média de 34,8 (variância 21-57). Todos com diagnóstico de esquizofrenia. No primeiro surto da doença os pacientes apresentavam idade média de 27,9 anos (variância 17-38) e os surtos subsequentes apareceram em média 4,1 $\pm 0,5$ anos após. Os pacientes foram orientados a receberem haloperidol (105 pacientes com dose entre 2 e $15 \mathrm{mg}$ ), clorpromazina (105 pacientes com dose entre 100 e $400 \mathrm{mg}$ ) e clozapina (115 pacientes com dose entre 75 e $600 \mathrm{mg}$ ). Os instrumentos psicométricos utilizados (GWB, PANSS e CGI) foram regularmente empregados durante os 5 anos do estudo. Resultados: Os 66 pacientes respondedores ao tratamento foram incluídos no protocolo de análise: 12, 10 e 16 apresentavam síndrome esquizofrênica positiva e 7, 6 e 15 síndrome negativa esquizofrênica com haloperidol, clorpromazina e clozapina, respectivamente. Diferenças estatísticas significantes foram observadas em todas as avaliações psicométricas em ambas sindromes esquizofrênicas favorecendo a clozapina. A distribuição de 18 tipos de efeitos colaterais observados foi diferente de modo significativo entre os 3 grupos estudados. A clozapina foi a droga que apresentou menos efeitos colaterais. Conclusão: A clozapina administrada por longo termo em pequenas doses em regime flexivel apresenta melhor eficácia nas síndromes esquizofrênicas quando comparada a outras drogas antipsicóticas.
\end{abstract}

PALAVRAS-CHAVE: esquizofrenia, drogas antipsicóticas, avaliação a longo termo, prática clínica.

Clinical Centre and Medical Faculty, Kragujevac, Serbia: 'Psychiatry Clinic; ${ }^{2}$ Department of Clinical and Experimental Pharmacology; ${ }^{3}$ Department of Neurology. Received 12 July 2008, received in final form 11 December 2008. Accepted 5 March 2009.

Dr.Dragan Ravanic - Psychiatry Clinic, Medical Faculty and Clinical Centre "Kragujevac" - Zmaj Jovina 30, 34000 Kragujevac, Serbia - E-mail: dravanic@sbb.co.yu 
The complexity of the long-term course of schizophrenia is confirmed in numerous researches'. When we consider pharmacological treatment of schizophrenia, it is quite clear that it represents one of the main dilemmas in psychiatric practice. The complexity of the problem is confirmed during a half-century struggle to find the drug with the best efficacy with minimal adverse effects in the treatment of schizophrenics. The activities in the field paralleled the researches in neurobiology of schizophrenia particularly neurophysiology, biochemistry and receptor pharmacology. The discovery of neuroleptic agents in 1950s was revolutionary and their introduction in clinical practice in 1960s allowed ex juvantibus approach to the understanding of the nature and function of dopaminergic pathways, which were the dominant target of these drugs.

The researches also showed that neuroleptics and other antipsychotic agents changed schizophrenia. They are specific for one or few symptoms but not for the disease per se ${ }^{1,2}$. Until 1980s the main therapeutic approach was diminishing clinical modalities, symptoms in psychopathology like hallucinations, delusions and thought disturbances. With the works of Crow and associates in the early 1980s and the concepts of dividing schizophrenia into type I and type $\mathrm{II}^{2}$ the new dilemmas emerged. The main problem was the question of chronic schizophrenia, particularly negative symptoms ${ }^{3}$. This gap between drug efficacy and the clinical need opened the possibility for further basic and clinical researches to define more valid and predictive criteria for antipsychotic use within both typical and atypical classes ${ }^{4}$.

Typical, incisive antipsychotic drugs were not capable to fulfill demands in the cure of negative schizophrenia, or they did it partially and with a lot of adverse effects. The introduction of novel, polyvalent, atypical antipsychotics opened an exciting research area, which dominated in both clinical and research practices during the late 1980s, and early 1990s. Both classes block a lot of amine receptors, but main differences emerged in dopaminergic $D_{2}$ pathways. The classical neuroleptics are strong $D_{2}$ antagonists but they display considerable affinity to other main neurotransmitter systems in brain. On the other hand, the atypical ones show less affinity for dopamine receptors, particularly for $D_{2}$, but potently ameliorate other receptor types ${ }^{5,6}$.

After decades of basic and clinical researches, clozapine has been established as a standard for the most severe type of this disorder, the treatment-resistant schizophrenia, as well as for chronic, frequently relapsing patients. However, there are still many debates about supremacy of other atypical drugs over earlier medication. In addition, mixed forms of disease in which positive and negative syndromes exist in parallel are still inadequately treated. It seems that heterogeneity of this subpopulation of schizophrenics was the basis of the problem. Unfortunately, these patients dominate in clinical practice and, obviously, they must be individually treated. The treatment algorithms, which are very useful for well-established and differentiated forms of schizophrenia, have little practical benefit. Further, similar long-term studies with clozapine are scarce and different from ours; for example they were of retrospective nature ${ }^{7}$, having different study population (e.g. females) ${ }^{8}$, including wide durations of followups $^{9}$ or aiming at isolated outcomes ${ }^{10}$.

Taking all this into account, our primary aims were to investigate the efficacy of three neuroleptics with different structure and pharmacological and clinical profile in the course of schizophrenic disorder in long term treatment, including the safety of the study medication in both positive and negative types of schizophrenia. The aim of our study also was to differentiate the effects of low doses of clozapine in flexible regime in comparison with two typical neuroleptics, haloperidol and chlorpromazine in long term.

\section{METHOD}

The clinical study was prospective, active-controlled with outpatients suffering from schizophrenia and the follow up of 5 years. Inclusion criteria were: adults over 18 years of age, both of genders, diagnosis of schizophrenia established by DSM-IV criteria, the presence of positive and negative symptoms, previously treated with antipsychotics which were inefficient and with the history of side effects. Previous antipsychotic drugs were different from the study antipsychotics. Exclusion criteria were: under 18 years of age, treatment naive schizophrenics, pregnant women, significant mental and/or somatic co-morbidity, schizophrenia lasting for 10 years or more and refusal of the patients themselves or her or his legal representative to participate in the study. The study was conducted during the period between 1998 and2003 at the Psychiatry Clinic of the Clinical Center Kragujevac. The allocation of the patients in three study arms followed pragmatic (naturalistic) design". It means that treatment allocation of study subjects was only governed by clinical practice criteria in our country, not by subject study status. Therefore, the patients were treated within the setting of regular clinical practice, at the cost of study which was incorporated into regular National Health Service funding scheme, and there was no need for any sponsorship (e.g. drugs, research stuff, psychiatrists).

The number of previous schizophrenia relapses, regardless to which antipsychotic drugs were previously prescribed, was the main criterion for particular antipsychotic choice. Haloperidol was assigned to patients having $<5$ relapses in the previous disease course and not receiving haloperidol before. Chlorpromazine was assigned to patients having $<5$ relapses in the previous disease course not receiving chlorpromazine before. The patients were allocated to clozapine if they had had five or more relapses in the previous disease course (not receiving clozapine before), 
as these patients were considered to be treatment-resistant. The presence of mild-to-moderate concomitant disease which could be worsened by study medication (e.g. metabolic syndrome, evidence of arrhythmias or ischemic heart disease, cardiomyopathy) was considered not to be any contraindication per se for study drugs and the patients with these disorders were initially treated with lower-doses of antipsychotic drugs with closer clinical follow-up every six months. They were allowed to have concomitant medications prescribed by appropriate specialist except for the interactions with haloperidol, chlorpromazine or clozapine. The drugs were used in approved indications and dose regimens. Participation in the study was completely voluntary, informed consent was obtained, and ethical principles were in accordance with Helsinki Declaration. The study design was considered and accepted by ethical board of the Psychiatry Clinic.

The three drugs were used as active treatment in mono-therapy. The first group of patients received haloperidol, in dose range 2-15 mg, daily, orally. The second group received chlorpromazine, in dose range of 100-400 mg, daily, orally. The final group received clozapine, in dose range $75-600 \mathrm{mg}$, daily, orally. Dose ranges were chosen according to the usual practice in our country ${ }^{12}$ and in accordance with some other authors ${ }^{8}$. Doses of all three drugs were adjusted according to clinical response. Daily doses were administered in one or more (generally in 2-3) portions. Other medications were used according to the clinical need, but this excluded other antipsychotic drugs.

The clinical efficacy was established using the following psychometric instruments: Positive and Negative Syndrome Scale-PANSS ${ }^{13}$, Clinical Global Impression Scale-CGI ${ }^{14}$ and Gen- eral Well-Being Scale-GWB ${ }^{15}$. The scale scores were calculated at baseline, after 6 weeks, 3 months, 12 months and annually. Aftermath, a number of patient visits was adjusted according to clinical need. In general, the visits at treatment introduction were weekly and after satisfactory clinical response, monthly. The safety of treatment was evaluated by CGI (subscale for recording and assessing every adverse clinical event). The patients were withdrawn from the study in the case of: no satisfactory clinical response, serious adverse effects or a patient withdrew on his or her own will.

Assessment of the general status (GWB) was estimated in the scale and scored by the psychiatrist from 0 (the worst) to 110 (the best). The PANSS scale scores were used to assess positive symptoms (PANSS-P), scored from 7 (the best) to 49 (the worst), negative symptoms (PANSS-N) scored from 7 to 49 and general psychopathology (PANSS-G) scored from 16 to 112. The CGI scale was used to score: a) severity of illness (SI) which defined the severity of illness, from 1 (normal) to 7 (most extremely ill), b) global improvement (GI), from 1 (very much improved) to 7 (very much worse) c) therapeutic effect (TE) from 1 (unchanged or worse) to 4 (vast improvement), and d) adverse effects (AE), from 1 (none) to 4 (outweigh therapeutic effect). Efficacy index (EI) was calculated by dividing the mean TE score with the mean $\mathrm{AE}$ score (El=TE/AE).

The study data was analyzed by the methods of descriptive statistics, t-test (for continuous numeric variables) and chisquare test (for frequencies) ${ }^{16}$. Hypothesis testing was done in two-sided procedure where the level of statistic significance was established at $\mathrm{p} \leq 0.05$.

Table 1. Demographic and clinical properties of the study population.

\begin{tabular}{lccc}
\hline Variable & Haloperidol group & Chlorpromazine group & Clozapine group \\
\hline Number of subjects & $105(100 \%)$ & $105(100 \%)$ & $115(100 \%)$ \\
Mean age at disease onset (range) & $29.09(17-41)$ & $28.09(19-38)$ & $24.52(19-32)$ \\
Mean age at study onset (range) & $34.71(23-57)$ & $38.52(21-56)$ & $33.60(24-55)$ \\
Gender (m/f) & $70 / 35$ & $60 / 45$ & $55 / 60$ \\
& $(66 \% / 34 \%)$ & $(57 \% / 43 \%)$ & $(48 \% / 52 \%)$ \\
Dominant negative symptoms & $35(34 \%)$ & $40(38 \%)$ & $50(44 \%)$ \\
Dominant positive symptoms & $70(66 \%)$ & $65(62 \%)$ & $65(56 \%)$ \\
Previous relapses & $3.7 \pm 0.5$ & $3.9 \pm 0.6$ & $5.3 \pm 0.5$ \\
Mean daily doses, mg (range) & & & $443.6(150-600)$ \\
During $1^{\text {st }}$ year & $9.2(6-15)$ & $358.4(100-400)$ & $158.4(75-450)$ \\
During $5^{\text {th }}$ year & $4.9(2-12)$ & $212.8(100-350)$ & $198.4(75-600)$ \\
During all study & $6.8(2-15)$ & $294.5(100-400)$ & 27 \\
Withdrawals at 1 year $(\mathrm{n})$ & 31 & 35 & 57 \\
Withdrawals in 2-5 years (n) & 55 & 54 & $31(26.9 \%)$ \\
Included in per-protocol analysis (n) & $19(18.1 \%)$ & 6 negative & 15 negative \\
& 7 negative & 10 positive & 16 positive \\
\hline
\end{tabular}


Table 2. The psychometric scores in the haloperidol group.

\begin{tabular}{|c|c|c|c|c|c|c|c|}
\hline Years & GWB & PANSS-P & PANSS-N & PANSS-G & SI & $\mathrm{Gl}$ & El \\
\hline \multicolumn{8}{|c|}{ Haloperidol group with dominant $\mathrm{SCH}+$} \\
\hline \multirow[t]{2}{*}{0} & 32.8 & 30.38 & 20.08 & 51.46 & 5.15 & - & - \\
\hline & \pm 7.04 & \pm 6.92 & \pm 5.62 & \pm 15.81 & \pm 1.08 & & \\
\hline \multirow[t]{2}{*}{1} & 48.12 & 23.86 & 16.62 & 45.77 & 4.77 & 3.25 & 0.79 \\
\hline & \pm 10.59 & \pm 5.91 & \pm 3.99 & \pm 9.46 & \pm 1.38 & \pm 0.88 & \pm 0.22 \\
\hline \multirow[t]{2}{*}{5} & 53.46 & 22.13 & 15.94 & 42.08 & 4.2 & 3.07 & 0.89 \\
\hline & \pm 15.39 & \pm 6.13 & \pm 3.65 & \pm 9.18 & \pm 1.06 & \pm 0.8 & \pm 0.26 \\
\hline \multicolumn{8}{|c|}{ Haloperidol group with dominant $\mathrm{SCH}-$} \\
\hline \multirow[t]{2}{*}{0} & 40.37 & 20.5 & 24.5 & 41.25 & 4.56 & - & - \\
\hline & \pm 8.48 & \pm 6.15 & \pm 6.13 & \pm 12.55 & \pm 1.15 & & \\
\hline \multirow[t]{2}{*}{1} & 47.75 & 18.5 & 22.45 & 39.54 & 4.18 & 3.25 & 0.71 \\
\hline & \pm 13.33 & \pm 4.47 & \pm 5.4 & \pm 11.27 & \pm 0.98 & \pm 0.66 & \pm 0.18 \\
\hline \multirow[t]{2}{*}{5} & 55.82 & 17.42 & 19.5 & 37.21 & 3.87 & 3 & 0.76 \\
\hline & \pm 16.52 & \pm 4.44 & \pm 4.63 & \pm 8.06 & \pm 0.8 & \pm 0.73 & \pm 0.17 \\
\hline
\end{tabular}

The values represent the mean ( \pm standard deviation); GWB: assessment of general status; PANSS-P: positive symptoms; PANSS-N: negative symptoms; PANSS-G: general psychopathology; SI: severity of illness; Gl: global improvement; El: Efficacy index; $\mathrm{SCH}( \pm)$ : dominant positive/negative symptoms.

Table 3. The psychometric scores in the chlorpromazine group.

\begin{tabular}{|c|c|c|c|c|c|c|c|}
\hline Years & GWB & PANSS-P & PANSS-N & PANSS-G & $\mathrm{SI}$ & $\mathrm{Gl}$ & $\mathrm{EI}$ \\
\hline \multicolumn{8}{|c|}{ Chlorpromazine group with dominant $\mathrm{SCH}+$} \\
\hline 0 & $\begin{array}{c}39 \\
\pm 11.7\end{array}$ & $\begin{array}{c}28.79 \\
\pm 6.7\end{array}$ & $\begin{array}{l}20.57 \\
\pm 6.04\end{array}$ & $\begin{array}{c}48.36 \\
\pm 13.06\end{array}$ & $\begin{array}{c}4.9 \\
\pm 1.25\end{array}$ & - & - \\
\hline 1 & $\begin{array}{l}49.64 \\
\pm 14.4\end{array}$ & $\begin{array}{l}23.86 \\
\pm 6.12\end{array}$ & $\begin{array}{r}18.86 \\
\pm 5.75\end{array}$ & $\begin{array}{l}38.93 \\
\pm 8.21\end{array}$ & $\begin{array}{c}4.22 \\
\pm 1.27\end{array}$ & $\begin{array}{c}3.36 \\
\pm 0.84\end{array}$ & $\begin{array}{r}0.69 \\
\pm 0.19\end{array}$ \\
\hline 5 & $\begin{array}{c}59.43 \\
\pm 16.05\end{array}$ & $\begin{array}{r}21.14 \\
\pm 5.71\end{array}$ & $\begin{array}{c}17.1 \\
\pm 5.09\end{array}$ & $\begin{array}{r}37.93 \\
\pm 9.97\end{array}$ & $\begin{array}{c}4.15 \\
\pm 0.98\end{array}$ & $\begin{array}{c}3.26 \\
\pm 0.84\end{array}$ & $\begin{array}{c}0.71 \\
\pm 0.17\end{array}$ \\
\hline \multicolumn{8}{|c|}{ Chlorpromazine group with dominant $\mathrm{SCH}-$} \\
\hline 0 & $\begin{array}{c}37.29 \\
\pm 10.52\end{array}$ & $\begin{array}{l}19.29 \\
\pm 5.4\end{array}$ & $\begin{array}{l}23.14 \\
\pm 6.71\end{array}$ & $\begin{array}{c}43 \\
\pm 11.67\end{array}$ & $\begin{array}{r}4.61 \\
\pm 1.16\end{array}$ & - & - \\
\hline 1 & $\begin{array}{l}49.29 \\
\pm 14.5\end{array}$ & $\begin{array}{c}17.71 \\
\pm 4.51\end{array}$ & $\begin{array}{l}20.57 \\
\pm 5.97\end{array}$ & $\begin{array}{c}39.45 \\
\pm 10.08\end{array}$ & $\begin{array}{c}4.02 \\
\pm 0.93\end{array}$ & $\begin{array}{c}3.21 \\
\pm 0.93\end{array}$ & $\begin{array}{r}0.73 \\
\pm 0.17\end{array}$ \\
\hline 5 & $\begin{array}{c}51.73 \\
\pm 15.05\end{array}$ & $\begin{array}{c}16.72 \\
\pm 4.07\end{array}$ & $\begin{array}{l}17.85 \\
\pm 4.71\end{array}$ & $\begin{array}{c}38.1 \\
\pm 8.44\end{array}$ & $\begin{array}{c}3.82 \\
\pm 0.87\end{array}$ & $\begin{array}{l}2.95 \\
\pm 0.7\end{array}$ & $\begin{array}{r}0.81 \\
\pm 0.18\end{array}$ \\
\hline
\end{tabular}

The values represent the mean ( \pm standard deviation); GWB: assessment of general status; PANSS-P: positive symptoms; PANSS-N: negative symptoms; PANSS-G: general psychopathology; SI: severity of illness; Gl: global improvement; El: Efficacy index; $\mathrm{SCH}( \pm)$ : dominant positive/negative symptoms.

\section{RESULTS}

The main demographic and clinical properties of the patients are presented in Table 1. In general, no significant heterogeneity among treatment groups was found and the groups were comparable according to the main clinical and demographic properties, at baseline.

The scores of psychometric variables are presented in details in Tables 2, 3 and 4. The mean difference between PANSS positive and negative sub scores was $29.1 \%$. For the purpose of calculation, three values of the total scores were used, at baseline, after a year and 5 years of treatment, according to the long-term outcome tracing. In general, the results showed the difference between study medications efficacy and the greatest and statistically significant clozapine efficacy. However, haloperidol and chlorpromazine were also efficacious, but with response variability in patients with positive and negative symptoms.

In the patients with positive schizophrenic syndrome, the comparison of clozapine with haloperidol and chlorpromazine showed greater efficacy of the former and statistical significance in the difference of all psychometric scores. However, in the PANSS-N sub scores and CGISI sub scores clozapine showed highly significant difference in effectiveness. In the patients with negative schizo- 
Table 4. The psychometric scores in the clozapine group.

\begin{tabular}{|c|c|c|c|c|c|c|c|}
\hline Years & GWB & PANSS-P & PANSS-N & PANSS-G & SI & GI & El \\
\hline \multicolumn{8}{|c|}{ Clozapine group with dominant $\mathrm{SCH}+$} \\
\hline \multirow[t]{2}{*}{0} & 32.62 & 32.15 & 24.24 & 52.77 & 5.74 & - & - \\
\hline & \pm 7.83 & \pm 6.93 & \pm 5.75 & \pm 13.72 & \pm 1.22 & & \\
\hline \multirow[t]{2}{*}{1} & 57.31 & 23.31 & 18.38 & 40.62 & 4.32 & 2.86 & 2.15 \\
\hline & \pm 15.47 & \pm 5.54 & \pm 4.96 & \pm 10.91 & \pm 1.21 & \pm 0.75 & \pm 0.58 \\
\hline \multirow[t]{2}{*}{5} & 59.15 & 21.97 & 15.88 & 36.12 & 3.91 & 2.25 & 3.2 \\
\hline & \pm 12.42 & \pm 5.27 & \pm 3.49 & \pm 9.53 & \pm 1.01 & \pm 0.55 & \pm 0.71 \\
\hline \multicolumn{8}{|c|}{ Clozapine group with dominant $\mathrm{SCH}-$} \\
\hline \multirow[t]{2}{*}{0} & 40.2 & 22.4 & 24.4 & 44.6 & 4.8 & - & - \\
\hline & \pm 11.26 & \pm 6.27 & \pm 6.59 & \pm 11.08 & \pm 1.2 & & \\
\hline \multirow[t]{2}{*}{1} & 57.4 & 18.8 & 18 & 33.75 & 3.62 & 2.4 & 2.09 \\
\hline & \pm 12.34 & \pm 5.45 & \pm 4.76 & \pm 9.13 & \pm 0.97 & \pm 0.62 & \pm 0.49 \\
\hline \multirow[t]{2}{*}{5} & 69.2 & 16.48 & 15.12 & 30.8 & 3.2 & 2.2 & 3.1 \\
\hline & \pm 16.58 & \pm 4.86 & \pm 4.4 & \pm 8.72 & \pm 0.95 & \pm 0.54 & \pm 0.75 \\
\hline
\end{tabular}

The values represent the mean ( \pm standard deviation); GWB: assessment of general status; PANSS-P: positive symptoms; PANSS-N: negative symptoms; PANSS-G: general psychopathology; SI: severity of illness; GI: global improvement; El: Efficacy index; $\mathrm{SCH}( \pm)$ : dominant positive/negative symptoms.

Table 5. Safety profiles of study drugs.

\begin{tabular}{|c|c|c|c|c|c|c|}
\hline \multirow[b]{2}{*}{ Adverse effects } & \multicolumn{2}{|c|}{ Haloperidol } & \multicolumn{2}{|c|}{ Chlorpromazine } & \multicolumn{2}{|c|}{ Clozapine } \\
\hline & $\mathrm{N}$ & $\%$ & $\mathrm{~N}$ & $\%$ & $\mathrm{~N}$ & $\%$ \\
\hline Dystonia & 67 & 30.3 & 22 & 6.7 & 1 & 1.0 \\
\hline Akathisia & 55 & 24.9 & 47 & 14.2 & 1 & 1.0 \\
\hline Bradikinesia & 16 & 7.2 & 68 & 20.6 & 14 & 14.6 \\
\hline Rigor & 52 & 23.5 & 19 & 5.8 & 0 & 0.0 \\
\hline Tremor & 27 & 12.2 & 24 & 7.3 & 2 & 2.1 \\
\hline Dyskinesia & 32 & 14.5 & 12 & 3.6 & 0 & 0.0 \\
\hline Sedation & 2 & 0.9 & 28 & 8.5 & 20 & 20.8 \\
\hline Convulsion & 3 & 1.4 & 3 & 0.9 & 1 & 1.0 \\
\hline Anticholinergic effects & 2 & 0.9 & 27 & 8.2 & 12 & 12.5 \\
\hline Hypersalivation & 2 & 0.9 & 6 & 1.8 & 11 & 11.5 \\
\hline Hypotension & 5 & 2.3 & 42 & 12.7 & 13 & 13.5 \\
\hline Arrhythmia & 1 & 0.5 & 5 & 1.5 & 3 & 3.1 \\
\hline Blood dyscrasia & 2 & 0.9 & 5 & 1.5 & 9 & 9.4 \\
\hline Hyperprolactinemia & 12 & 5.4 & 9 & 2.7 & 1 & 1.0 \\
\hline Weight changes & 3 & 1.4 & 8 & 2.4 & 4 & 4.2 \\
\hline Dyslipidemia & 4 & 1.8 & 4 & 1.2 & 2 & 2.1 \\
\hline Glucose intolerance & 1 & 0.5 & 1 & 0.3 & 2 & 2.1 \\
\hline Skin reactions & 2 & 0.9 & 4 & 1.2 & 1 & 1.0 \\
\hline Total & 221 & 100 & 330 & 100 & 96 & 100 \\
\hline $\begin{array}{l}\text { Number of adverse } \\
\text { events per patient }\end{array}$ & 2.7 & & 3.2 & & 0.9 & \\
\hline
\end{tabular}

$\mathrm{N}$ : number of patients experiencing the reaction; distribution significantly differed $\left(\chi^{2}=315.7, \mathrm{df}=34, \mathrm{p}<0.001\right)$. 
phrenic syndrome, the comparison of clozapine with haloperidol and chlorpromazine showed much greater efficacy of the former and greater statistical significance in the difference of all psychometric scores. Therefore, the t-test values of differences for mean absolute changes of psychometric scores between haloperidol $(n=12)$ group and clozapine group $(n=16)$ in positive schizophrenic syndrome at the final visit (after 5 years of treatment) for GWB, PANSS-P, PANSS-N, PANSS-G, PANSS-T, and $\mathrm{SI}$ were $2.21(\mathrm{df}=26, \mathrm{p}<0.05), 2.11(\mathrm{df}=26, \mathrm{p}<0.05), 2.94$ $(d f=26, p<0.01), 2.71(d f=26, p<0.05), 2.76(d f=26, p<0.05)$, and $2.85(\mathrm{df}=26, \mathrm{p}<0.01)$, respectively. The t-test values for the same scales in negative schizophrenic syndrome ( 7 and 15 patients) were $2.86(\mathrm{df}=20, \mathrm{p}<0.01), 2.87(\mathrm{df}=20$, $\mathrm{p}<0.01), 2.85$ ( $d f=20, p<0.01), 3.84(\mathrm{df}=20, \mathrm{p}<0.01), 3.22$ $(d f=20, p<0.01), 2.97$ and $(d f=20, p<0.01)$. The t-test values of differences for mean absolute changes of psychometric scores between chlorpromazine $(n=10)$ group and clozapine group $(n=16)$ in positive schizophrenic syndrome at the final visit (after 5 years of treatment) for GWB, PANSS-P, PANSS-N, PANSS-G, PANSS-T, and SI were 2.15 $(\mathrm{df}=24, \mathrm{p}<0.05), 2.37(\mathrm{df}=24, \mathrm{p}<0.05), 2.88(\mathrm{df}=24, \mathrm{p}<0.01)$, $2.43(d f=24, p<0.05), 2.64(d f=24, p<0.05)$, and $2.89(d f=24$, $p<0.01)$, respectively. The t-test values for the same scales in negative schizophrenic syndrome ( 6 and 15 patients) were 3.12 ( $d f=19, p<0.01), 3.42(d f=19, p<0.01), 2.91(d f=19$, $p<0.01), 3.89$ (df=19, $p<0.01), 3.41$ (df=19, $p<0.01$ ), and 3.14 $(d f=19, p<0.01)$, respectively.

More adverse effects were reported in the chlorpromazine group ( 3.2 drug adverse reactions per patients), than in subjects who received haloperidol (2.7) and clozapine (0.9) (Table 5). The difference in the types of adverse effects frequency was highly statistically significant $\left(\chi^{2}=315.7, d f=34, p<0.001\right)$. Adjuvant medication was used only in the case of adverse reaction treatment when other measures were ineffective (e.g. dose adjustment). Hence, concomitant drugs were used intermittently if reaction was of moderate-to-severe intensity. Anticholinergic drugs were used for the treatment of extrapyramidal reactions in total of 55 patents receiving haloperidol (52.4\%), 61 patients receiving chlorpromazine $(58.1 \%)$ and 29 patients receiving clozapine (27.6\%). Benzodiazepines were used for the treatment of both extrapyramidal reactions and anticonvulsants in total of 31 patents receiving haloperidol (29.5\%) 38 patients receiving chlorpromazine (36.2\%), and 7 patients receiving clozapine (6.7\%). Non-benzodiazepine hypnotics were used in total of 36 patents receiving haloperidol (34.3\%), 3 patients receiving chlorpromazine $(2.9 \%)$ and 2 patients receiving clozapine (1.9\%). Sympathomimetics were used as vasoconstrictors in the case of profound hypotension in total of 3 patents receiving haloperidol (2.9\%), 31 patients receiving chlorpromazine (29.5\%) and 39 patients receiving clozap- ine (37.1\%). The difference among the drugs in the use of adjuvant medication was highly significant $\left(\chi^{2}=84.8, d f=6\right.$, $\mathrm{p}<0.001)$.

\section{DISCUSSION}

Our results showed that clozapine, in low doses of flexible regime, in long term, in chronic schizophrenics with positive and negative syndrome was significantly more effective in comparison with typical antipsychotics, haloperidol and chlorpromazine. In two psychometric modalities of positive syndrome, PANSS-N and CGI-SI, clozapine showed even greater effects. It means that clozapine was more effective drug in reducing manifest psychopathology in positive schizophrenic syndrome, making them more socially adaptable, as indicated in general well being mode. The effects of clozapine in negative schizophrenic syndrome were similar but with much greater magnitude than in positive syndrome.

It is well reported that in randomized clinical trials clozapine was more effective than comparator, typical antipsychotic drug particularly in treatment-resistant cases ${ }^{17}$. In addition, patients were more satisfied with clozapine treatment than with typical neuroleptic treatment ${ }^{18}$. Clozapine also significantly reduces suicidal, aggressive and impulsive behavior ${ }^{19}$. However, the recent meta-analysis revealed that, within the clinical trial setting, the benefits of clozapine compared with conventional treatment may not be as extensive as previously thought ${ }^{20}$. The insufficient duration of the follow-up, heterogeneity between clinical trials and disclosed or hidden commercial conflict of interests may bias earlier reports. In addition, the effectiveness of typical neuroleptic drugs in long-term, real clinical practice could be substantially compromised with the development of many adverse effects, particularly extrapyramidal reactions. The pragmatic trial design, for which the renewal of interest is noted ${ }^{21}$, represents suitable model in searching for enduring outcomes. Certainly, our results showed great statistical difference in the frequency of adverse effects after five years, when clozapine and comparators are considered. In the long-term study, clozapine showed fewer and fewer side effects in time, which influenced its clinical efficacy as perceived by both the patient and clinician. Other authors also address the need for long-term pragmatic community trials in which the effectiveness of clozapine should be investigated particularly in special patient populations ${ }^{17}$. In a study similar to ours, it has also been reported that clozapine had very positive clinical effects during five-year period ${ }^{22}$.

Our results, concerning the safety profile of clozapine, are in agreement with other studies within ambulatory, long-term setting ${ }^{23}$. Neither the cases of significant blood disorders nor the cases of muscle damage were detected in our patients. Similarly, only in $2.1 \%$ of medically healthy pa- 
tients with schizophrenia treated with clozapine on a longterm basis, the signs of myotoxicity were found ${ }^{24}$. In another study, tachycardia, hypotension and sedation disappeared during the initial phase of treatment (i.e. 4-6 weeks), as tolerance developed with continuation of therapy ${ }^{12}$. In our study we were not particularly concerned with specific measures of the patients' quality of life. However, our approach followed the clinical effects of clozapine in multidimensional pattern, as others suggested ${ }^{25}$. Overall, all measures confirmed the effectiveness and safety of clozapine.

The selection bias, high drop out rate and mean doses are potential study limitations. The patients in clozapine group had some more relapses at baseline and somewhat higher psychometric scores, but this was not statistically significant. Nevertheless, this fact might suggest the presence of a selection bias which could potentially distort final results. However, the bias did not diminish the clozapine efficacy at the end of study, likely due to its more polyvalent, unique receptor pharmacology than other antipsychotic drugs ${ }^{26}$. The selective changes in neurotransmission produced by clozapine antipsychotic action were rather time-dependent than dose-dependent, which may be a reason of delayed therapeutic activity ${ }^{27}$ and also the effectiveness of moderate to low doses in our study.

In our study, the high drop out rate noted, but this fact correlates well with other studies in both first-episode schizophrenia ${ }^{28}$ and particularly chronic schizophrenic patients ${ }^{29}$. The most frequent reasons for discontinuation were a drug's insufficient effectiveness, adverse effects, or the patient's noncompliance. Therefore, as it is well-known that drop out rate, in general, was rather high and increased during the study, we analyzed responsive subjects only (per-protocol analysis) because we were interested only in drug effectiveness on subtitle psychometric modalities but not in drug's effects on the whole study population. In randomized controlled trials, high doses of the second generation of atypical antipsychotics including clozapine were used to produce all or almost all the clinical responses for the drug ${ }^{30}$. Although in rare cases we used very high doses, in the majority of patients clozapine mean doses were smaller. However, our study was performed in naturalist settings in which flexible, rather fixed doses are more appropriate ${ }^{12}$. Other studies confirmed the effectiveness of clozapine in flexible dose schedules during the long term therapy ${ }^{31,32}$, and also including very small doses ${ }^{8}$.

In conclusion, the long term, five-year use of low dose of atypical antipsychotic, clozapine, in flexible regime, gives satisfying clinical effectiveness and shows its superiority to haloperidol and chlorpromazine. The safety profile of clozapine was better than other study drugs. Our study confirmed the need for designing and conducting the long-term, clinical studies in naturalistic, routine clinical practice settings with multidimensional approach.

\section{REFERENCES}

1. Carpenter WT, Kirkpatrick B. The heterogeneity of the long-term course of schizophrenia. Schizophr Bull 1988;14: 645-652.

2. Crow TJ. Positive and negative schizophrenic symptoms and the role of dopamine. Br Psychiatry 1980;137:383-386.

3. Angst J. European long-term follow-up studies in schizophrenia. Shizophr Bull 1988;14:501-513.

4. Meltzer HY, Sommers AA, Luchins DJ. The effects of neuroleptics and other psychotropic drugs on negative symptoms in schizophrenia. J Clin Psychopharmacology 1986;6:329-338.

5. Lindstrom IH. The effects of long-term treatment with clozapine in schizophrenia: a retrospective study in 96 patients treated with clozapine for up to 13 years. Acta Psychiatr Scand 1987;77:524-529.

6. Tandon R, Goldman RS, Goodson J, Greden JF. Mutability and relationships between positive and negative symptoms during neuroleptic treatment in schizophrenia. Biol Psychiatry 1990;27:1323-1326.

7. Ahn YM, Chang JS, Kim Y, et al. Reduction in hospital stay of chronic schizophrenic patients after long-term clozapine treatment. Int Clin Psychopharmacol 2005;20:157-161.

8. Schmauss M, Wolff R, Erfurth A, et al. Tolerability of long term clozapine treatment. Psychopharmacology (Berl) 1989;99 (Suppl):S105-S108.

9. Gelly F, Chambon O, Marie-Cardine M. Long-term clinical experience with clozapin. Encephale 1997;23:385-396.

10. Procyshyn RM, Wasan KM, Thornton AE, et al. Changes in serum lipids, independent of weight, are associated with changes in symptoms during long-term clozapine treatment. J Psychiatry Neurosci 2007;32:331-338.

11. Ciapparelli A, Dell'Osso L, Bandettini di Poggio A, et al. Clozapine in treatment-resistant patients with schizophrenia, schizoaffective disorder, or psychotic bipolar disorder: a naturalistic 48-month follow-up study. J Clin Psychiatry 2003;64:451-458.

12. Marinkovic D, Timotijevic I, Babinski T, Totic S, Paunovic VR. The side-effects of clozapine: a four-year follow-up study. Prog Neuropsychopharmacol Biol Psychiatry 1994;18:537-544.

13. Kay SR, Fiszbein A, Opler LA. The positive and negative syndrome scale (PANSS) for schizophrenia. Shizophr Bull 1987;13:261-276.

14. Guy W. ECDEU Assessment Manual for Psychopharmacology - Revised (DHEW Publ No ADM 76-338). Rockville: U.S. Department of Health, Education, and Welfare, Public Health Service, Alcohol, Drug Abuse, and Mental Health Administration, NIMH Psychopharmacology Research Branch, Division of Extramural Research Programs, 1976:218-222.

15. Norman RM, Malla AK, McLean T, et al. The relationship of symptoms and level of functioning in schizophrenia to general wellbeing and the Quality of Life Scale. Acta Psychiatr Scand 2000;102:303-309.

16. Altman DG. Practical statistics for medical research. London: Chapman and Hall, 1991. 
17. Wahlbeck K, Cheine M, Essali A, Adams C. Evidence of clozapine's effectiveness in schizophrenia: a systematic review and meta-analysis of randomized trials. Am J Psychiatry 1999;156:990-999.

18. Wahlbeck K, Cheine M, Essali MA. Clozapine versus typical neuroleptic medication for schizophrenia. Cochrane Database Syst Rev 2000;2:CD000059.

19. Spivak B, Shabash E, Sheitman B, Weizman A, Mester R. The effects of clozapine versus haloperidol on measures of impulsive aggression and suicidality in chronic schizophrenia patients: an open, nonrandomized, 6-month study. J Clin Psychiatry 2003;64:755-760.

20. Moncrieff J. Clozapine v. conventional antipsychotic drugs for treatment-resistant schizophrenia: a re-examination. Br J Psychiatry 2003;183:161-166.

21. Vallve C. A critical review of the pragmatic clinical trial. Med Clin (Barc) 2003;121:384-388

22. Drew LR, Griffiths KM, Hodgson DM. A five year follow-up study of the use of clozapine in community practice. Aust $\mathrm{N}$ Z J Psychiatry 2002;36:780-786.

23. Peacock L, Solgaard T, Lublin H, Gerlach J. Clozapine versus typical antipsychotics. A retro- and prospective study of extrapyramidal side effects. Psychopharmacology (Berl) 1996; 124:188-196.

24. Reznik I, Volchek L, Mester R, et al. Myotoxicity and neurotoxicity during clozapine treatment. Clin Neuropharmacol 2000;23:276-280

25. Awad AG, Voruganti LN, Heslegrave RJ. Measuring quality of life in patients with schizophrenia. Pharmacoeconomics 1997; 11:32-47.

26. Kalkman HO, Loetscher E. $\alpha 2 \mathrm{C}$-Adrenoceptor blockade by clozapine and other antipsychotic drugs. Eur J Pharmacol 2003;462;33-40.

27. Shilliam CS, Dawson LA. The effect of clozapine on extracellular dopamine levels in the shell subregion of the rat nucleus accumbens is reversed following chronic administration: comparison with a selective 5-HT(2C) receptor antagonist. Neuropsychopharmacology 2005;30:372-380.

28. Kahn RS, Fleischhacker WW, Boter H, et al. for the EUFEST study group. Effectiveness of antipsychotic drugs in first-episode schizophrenia and schizophreniform disorder: an open randomised clinical trial. Lancet 2008;371:1085-1097.

29. Lieberman JA, Stroup TS, McEvoy JP, et al. Clinical Antipsychotic Trials of Intervention Effectiveness (CATIE) Investigators. Effectiveness of antipsychotic drugs in patients with chronic schizophrenia. N Engl J Med 2005;353:1209-1223.

30. Davis JM, Chen N. Dose response and dose equivalence of antipsychotics. J Clin Psychopharmacol 2004;24:192-208.

31. Martin JL, Pérez V, Sacristán M, Rodríguez-Artalejo F, Martínez C, Alvarez E. Meta-analysis of drop-out rates in randomised clinical trials, comparing typical and atypical antipsychotics in the treatment of schizophrenia. Eur Psychiatry 2006;21:11-20.

32. Advokat CD, Bertman LJ, Comaty JE Jr. Clinical outcome to clozapine treatment in chronic psychiatric inpatients. Prog Neuropsychopharmacol Biol Psychiatry 1999;23:1-14. 